\title{
A rapid diagnostic test for schistosomiasis mansoni
}

\author{
Clélia Christina Mello-Silva', Roberto Carlos João ${ }^{2,3}$, \\ Ronaldo de Carvalho Augusto ${ }^{1,2}$, Claudia Portes Santos ${ }^{2 /+}$
}

'Laboratório de Esquistossomose Experimental 'Laboratório de Avaliação e Promoção da Saúde Ambiental, Instituto Oswaldo Cruz-Fiocruz, Rio de Janeiro, RJ, Brasil ${ }^{3}$ Hospital Central Dr António Agostinho Neto do Estado da Huíla, Lubango, Angola

This article presents an improvement to the Kato-Katz (KK) method, making it faster and more efficient for the visualisation of fertile eggs in stool samples. This modified KK method uses sodium acetate formalin as a fixative and reveals the intensity of infection in less than $1 \mathrm{~h}$, reducing the diagnostic time without increasing the cost. This modified method may contribute to future epidemiological studies in both hospitals and the field due to its rapid and precise diagnostic, which allow for immediate treatment.

Key words: modified Kato-Katz method - parasitological technique - schistosomiasis diagnosis

Although various techniques have been used to diagnose schistosomiasis, the World Health Organization recommends the use of the Kato-Katz (KK) method for monitoring and control programs, mainly in endemic areas (Katz et al. 1972, Rabello et al. 2008). The traditional KK (tKK) method is a simple quantitative parasitological technique considered to have low cost and of easy procedure. It is currently the best technique for the diagnosis of schistosomiasis in field studies. However, several limiting factors have been identified for tKK, including its requirement of waiting at least $1 \mathrm{~h}$ before slides can be examined (according to the manufacturer's instructions), its incompatibility with liquid stools and its difficulties in visualising fertile eggs. The purpose of this study was to develop an improvement to the KK method, making it faster and more efficient in the visualisation of fertile eggs in stool samples.

Thirty mice infected with Schistosoma mansoni, obtained from three different experimental infections, were used to compare the number of eggs per gram (EPG) of stool by two methods: the tKK method and our newly proposed modified KK (mKK) method using sodium acetate formalin (SAF) as a fixative. This research was licensed by the Animal Ethical Committee of the Oswaldo Cruz Foundation (LW-L-63/08-9/2012) in accordance with the guidelines of the Brazilian College for Animal Experiments.

The tKK method was performed according to the original guidelines (Katz et al. 1972). The mKK method initially followed the tKK method protocol in its use of nylon mesh and a perforated plate, but $100 \mu \mathrm{L}$ of SAF

doi: $10.1590 / 0074-0276130335$

Financial support: IOC-FIOCRUZ, FESA/Angola, CAPES/Parasitologia Básica, PROCAD-NF

+Corresponding author: cpsantos@ioc.fiocruz.br

Received 25 June 2013

Accepted 3 September 2013
(1.5 g of sodium acetate, $3 \mathrm{~mL}$ of acetic acid, $5 \mathrm{~mL}$ of $40 \%$ formalin and $90.5 \mathrm{~mL}$ of distilled water) (Junod 1972) was then added to the standardised faecal sample remaining on the slide. A glass cover slide $(24 \times 30 \mathrm{~mm})$ was placed over the sample and carefully pressed rather than using a cellophane pre-stained cover slide.

Slides prepared according to each method were studied at the moment of slide preparation (0) and after $12 \mathrm{~h}$ and $24 \mathrm{~h}$ to evaluate the effectiveness of these methods at different time intervals (Fig. 1A). This experiment was repeated once.

Slides prepared according to each method were then observed after $1 \mathrm{~h}$ and $24 \mathrm{~h}$, simulating field study procedures (Fig. 1B). The results of both methods were analysed in relation to the time and quality of visualisation. Due to the absence of normality of the data, the KruskalWallis test was used for statistical evaluation (Graph Pad v.3.02) at $95 \%$ validity and only $5 \%$ error.

As expected, when samples were prepared according to the traditional method (tKK), it was not possible to observe the eggs at the moment of slide preparation. The use of the mKK, however, allowed the fertile eggs to be observed immediately and clearly. In the first experiment, the EPG under the mKK method at the time of preparation was $7.7 \%$ higher than under the tKK method at $24 \mathrm{~h}$, without a significant difference. However, after $12 \mathrm{~h}$, the two methods produced similar results with no significant differences. Comparing the two methods after $24 \mathrm{~h}$, the EPG under the tKK method was $44 \%$ higher than under the mKK method. The EPG results for each technique at different time points are displayed in Fig. 1A.

The second experiment revealed that the EPG under the mKK method at $1 \mathrm{~h}$ was $13.1 \%$ higher than under the tKK method at $24 \mathrm{~h}$. During the first hour using the tKK method, the eggs could not be observed. After $24 \mathrm{~h}$, the EPG under the tKK method was $32.6 \%$ higher than under the mKK method (Fig. 1B).

The highest quality $S$. mansoni eggs were observed from the time of preparation to $1 \mathrm{~h}$ after slide preparation using the mKK method (Fig. 2A), in contrast with 
A

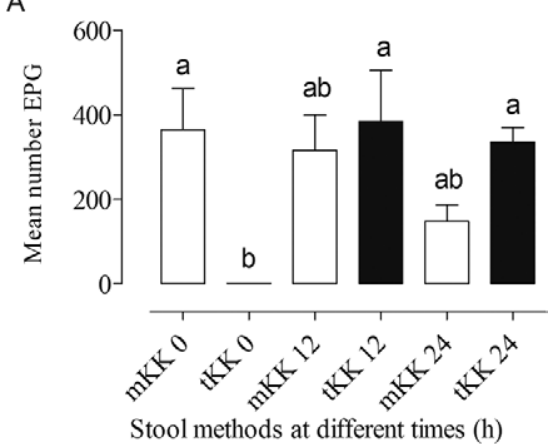

B

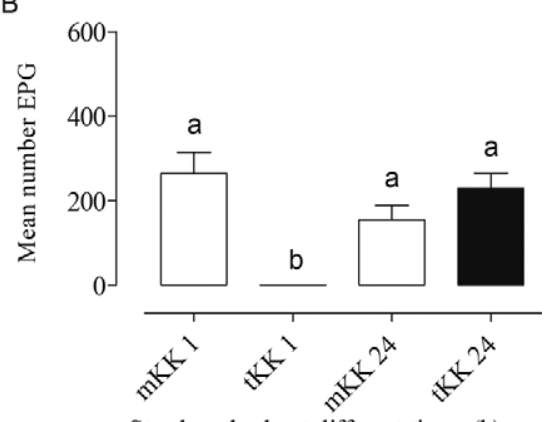

Stool methods at different times (h)

Fig. 1: number of eggs per gram (EPG) of stool using modified KatoKatz (mKK) and traditional KK (tKK) methods in different infections at different times. Different letters indicate significant results. A: $0 \mathrm{~h}$, $12 \mathrm{~h}$ and $24 \mathrm{~h} ; \mathrm{B}: 1 \mathrm{~h}$ and $24 \mathrm{~h}$.

both methods after $24 \mathrm{~h}$ (Fig. 2B-E). These precise and rapid diagnostic improvement may be useful for future epidemiological field studies applying the mKK method. The use of SAF aids in the rapid clarification of samples, allowing for the quick visualisation of miracidia within eggs.

In addition to the $\mathrm{KK}$ method, other tests have been employed to diagnose schistosomiasis, including the TF-Test, Koga agar method, ether-concentration technique, FLOTAC test, Baermann-Moraes test and Hoffman-Pons-Janer test (Utzinger et al. 2008, Glinz et al. 2010, Knopp et al. 2011, Siqueira et al. 2011, de Carvalho et al. 2012). The FLOTAC test is more sensitive in detecting protozoan and helminth infections than the KK method due to the use of SAF. However, the cost and the time required are higher than for the KK (Utzinger et al. 2008).

Tests using circulating $S$. mansoni antigens in the urine as circulating anodic (CAA) and cathodic antigens (CCA) have been described as an alternative to the KK technique (Berquist 2013). Coulibaly et al. (2011) reported that a CCA assay showed similar sensitivity to the KK method in triplicate for the diagnosis of $S$. mansoni. Based on our comparison of the tKK and the mKK methods, this new method would likely show similar results if compared to the commercially available CCA cassette test, but at a lower cost and with faster results.
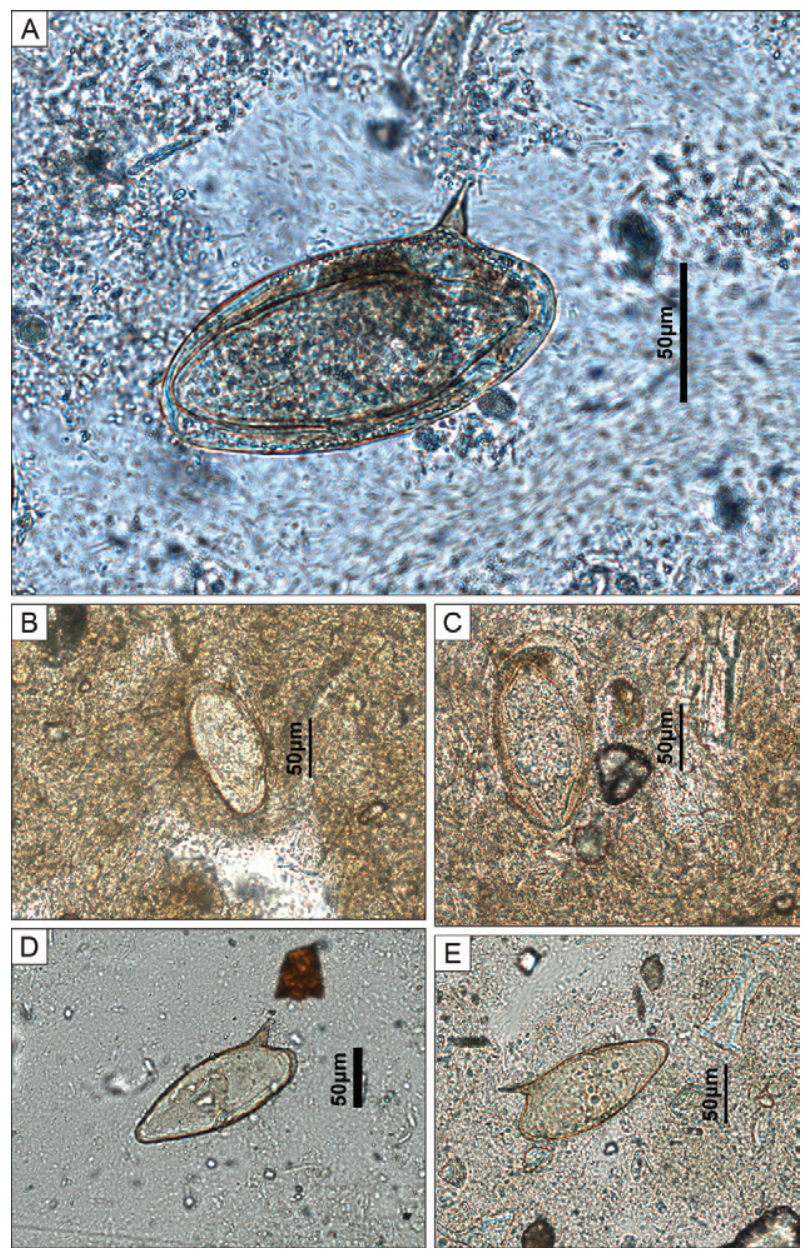

Fig. 2: micrographs of Schistosoma mansoni eggs by light microscopy. A: modified Kato-Katz (mKK) method observed in the first hour, miracidium in detail; B, C: $\mathrm{mKK} 24 \mathrm{~h}$; D, E: traditional KK method $24 \mathrm{~h}$

A multiplex real-time polymerase chain reaction assay for the detection and quantification of S. mansoni DNA is an alternative approach to investigating the epidemiology of schistosomiasis. That method proved to be sensitive, but produced similar results as the KK method (ten Hove et al. 2008). Although this method is considered a powerful diagnostic tool for epidemiological studies of schistosomiasis, it is expensive and requires specific equipment. In contrast, the $\mathrm{mKK}$ method is a rapid and low-cost approach.

In conclusion, the use of SAF in the mKK method reduced the time of diagnosis without increasing the cost. Moreover, egg visualisation was clearer with the mKK method than with the traditional method. This mKK method provides data on the intensity of infection in less than $1 \mathrm{~h}$ without a significant difference from the results of the tKK method at $24 \mathrm{~h}$. This modified method may contribute to future epidemiological studies both in hospitals and in the field due to its rapid and precise diagnostic capabilities that facilitate immediate treatment. 


\section{REFERENCES}

Berquist R 2013. Good things are worth waiting for. Am J Trop Med Hyg 88: 409-410.

Coulibaly JT, Knopp S, N'Guessan NA, Furst T, Lohourignon LK, Brou JK, N'Gbesso YK, Vounatsou P, N'Goran EK, Utzinger J 2011. Accuracy of urine circulating cathodic antigen (CCA) test for Schistosoma mansoni diagnosis in different settings of Côte d'Ivoire. PLoS Negl Trop Dis 5: el384.

de Carvalho GLX, Moreira LE, Pena JL, Marinho CC, Bahia MT, Machado-Coelho GLL 2012. A comparative study of the TFTest ${ }^{\circledR}$, Kato-Katz, Hoffman-Pons-Janer, Willis and BaermannMoraes coprologic methods for the detection of human parasitosis. Mem Inst Oswaldo Cruz 107: 80-84.

Glinz D, Silué KD, Knoop S, Lohouignon LK, Yao KP, Steinmann P, Rinaldi L, Cringoli G, N'Goran EK, Utzinger J 2010. Comparing diagnostic accuracy of Kato Katz, Koga Agar plate, etherconcentration and FLOTAC for Schistosoma mansoni and soiltransmitted helminths. PLoS Negl Trop Dis 4: e754.

Junod C 1972. Technique coprologique nouvelle essentiellement destinée a la concentration des trophozoites d'amibes. Bull Soc Pathol Exot Filiales 65: 390-398.

Katz N, Chaves A, Pellegrino J 1972. A simple device for quantitative stool thick smear technique in Schistosomiasis mansoni. Rev Inst Med Trop São Paulo 14: 397-340.
Knopp S, Speich B, Hattendorf J, Rinaldi L, Mohammed KA, Albonico M, Rollinson D, Marti H, Cringoli G, Utzinger J 2011. Diagnostic accuracy of Kato Katz and FLOTAC for assessing anthelmintic drug efficacy. PLoS Negl Trop Dis 5: e1036.

Rabello A, Pontes LA, Enk MJ, Montenegro SML, Morais CNL 2008. Diagnóstico parasitológico, imunológico e molecular da esquistossomose mansoni. In OS Carvalho, PMZ Coelho, HL Lenzi, Schistosoma mansoni \& esquistossomose, Fiocruz, Rio de Janeiro, p. 897-925.

Siqueira LMV, Coelho PMZ, de Oliveira AA, Massara CL, Carneiro NFF, Lima ACL, Enk MJ 2011. Evaluation of two coproscopic techniques for the diagnosis of schistosomiasis in a low-transmission area in the state of Minas Gerais, Brazil. Mem Inst Oswaldo Cruz 106: 844-850.

ten Hove RJ, Verweij JJ, Vereecken K, Polman K, Dieye L, Lieshout L 2008. Multiplex real-time PCR for the detection and quantification of Schistosoma mansoni and S. haematobium infection in stool samples collected in northern Senegal. Trans $R$ Soc Trop Med Hyg 102: 179-185.

Utzinger J, Rinaldi L, Lohourignon LK, Rohner F, Zimmermann MB, Tschannen AB, Goran EKN, Cringoli G 2008. FLOTAC: a new sensitive technique for the diagnosis of hookworm infections in humans. Trans R Soc Med Hyg 102: 84-90. 